ISSN 1822-427X/eISSN 1822-4288 2019 Volume 14 Issue 3: 341-359 https://doi.org/10.7250/bjrbe.2019-14.447
THE BALTIC JOURNAL

\title{
MODEL FOR PREDICTING \\ ROAD MARKINGS SERVICE LIFE
}

\section{DARIO BABIĆ*, ANĐELKO ŠČUKANEC, DARKO BABIĆ, MARIO FIOLIĆ \\ Dept of Traffic Signalling, Faculty of Transport and Traffic Sciences, University of Zagreb, Zagreb, Croatia}

Received 28 February 2019; accepted 15 April 2019

\begin{abstract}
Road markings provide drivers with the information necessary for their comfortable and safe journey. To achieve that, they must be visible in all driving conditions, which means that they have to be renewed and maintained in a timely manner. This research aims to develop a model for predicting the service life of paint, thermoplastic and agglomerate cold plastic road markings. The research comprised $5218.00 \mathrm{~km}$ (115 roads) of solvent-borne paint road markings, $579.00 \mathrm{~km}$ (30 roads) of thermoplastic and $4979.00 \mathrm{~km}$ (30 roads) of agglomerate cold plastic road markings. The retroreflectivity of road markings was measured two times (after renewal and after winter) using the dynamic measuring method. Service life prediction model was developed for each material based on factors such as initial retroreflectivity, road marking age and position, annual average daily traffic and winter maintenance activity of the road. Developed models were tested using a new data set, and all three models showed satisfactory accuracy. The application of the model enables road authorities to optimise road-marking maintenance activities, while at the same time, ensuring the level of visibility required by drivers.
\end{abstract}

Keywords: nighttime visibility, retroreflectivity, road asset management, road markings, service life, traffic safety.

\footnotetext{
* Corresponding author. E-mail: dario.babic@fpz.hr

Dario BABIĆ (ORCID ID 0000-0003-2476-5940)

Anđelko ŠČUKANEC (ORCID ID 0000-0001-6064-9870)

Darko BABIĆ (ORCID ID 0000-0003-4381-1674)

Mario FIOLIĆ (ORCID ID 0000-0001-9483-1910)
} 


\section{Introduction}

Road traffic accidents are a significant social problem, and it is estimated that, depending on the country, their costs amount from $1 \%$ up to $3 \%$ of the gross domestic product (World Health Organization, 2017). For this reason, many countries have developed action plans to reduce the number of fatalities on the roads. The main guidelines of these action plans are aimed at improving all the elements that can contribute to increasing road safety, including the traffic infrastructure in which road markings are an important element as part of traffic control plan.

In general, road markings form the road surface by using and combining lines, signs and symbols and provide information concerning visual guidance to road users (Babić, Ščukanec, \& Babić, 2016). Since their first documented use along the Trenton River Road in Michigan in 1911, road markings have become a conventional element of traffic infrastructure (Industrial Commercial Striping, 2015). As they are positioned in the drivers central field of vision, they are also an important element contributing to road safety. Namely, previous research suggests that road markings to a certain extent affect the driver behaviour in terms of changing the lateral position of the vehicle and driving speed, providing them with a better visual guidance along the entire road section (Davidse, van Driel, \& Goldenbeld, 2004; Retting \& Farmer, 1998; Shinar, Rockwell, \& Malecki,1980).

However, to be able to provide drivers with a high level of visual guidance and effectively perform their function, thereby contributing to increasing road safety, road markings must be maintained in a timely and appropriate manner. Due to the complexity of road traffic accidents, it is difficult fully to determine the impact of road markings on the frequency of their occurrence. However, it is generally believed that inadequate and poorly maintained road markings, or road markings with a low level of retroreflectivity, are a significant factor contributing to their occurrence, which is partly confirmed by scientific research (Avelar \& Carlson, 2014; Bektas, Gkritza, \& Smadi, 2016; Carlson, Park, \& Kang, 2013; Miller, 1992; Smadi, Hawkins, Nlenanya, \& Aldemir-Bektas, 2010; Smadi, Souleyrette, Ormand, \& Hawkins, 2008).

To optimise the maintenance system, that is, to ensure a satisfactory level of road markings visibility and thus their service life, while minimising maintenance costs, it is necessary to analyse the road, geographic and meteorological conditions of the area in which the road is located. The use of appropriate technologies and materials for road marking application, considering the above conditions, will contribute to 
maintaining the required level of visibility and thereby directly increase the overall road safety.

Precisely for the above reasons, this research aims to develop models for predicting the service life of road markings based on the analysis of the impact of relevant factors on the degradation of their retroreflectivity. The research included 115 single carriageway state roads with solvent-borne paint road markings and 30 single carriageway state roads with thermoplastic and agglomerate cold plastic road markings. This research is the first large-scale research that uses the dynamic method to collect data on road markings retroreflectivity. Furthermore, the model for predicting the service life of agglomerate cold plastic road markings is the first such model available in the literature, as far as it is known to authors of this scientic paper. The purpose of the obtained models is to broaden the existing scientific knowledge and understanding of road markings on the one hand and to optimise the road maintenance system in terms of rationalisation of costs associated with the road markings renewal and ensuring the appropriate visibility required by the drivers on the other hand.

\section{Literature review}

Road markings service life is one of the basic parameters for comparing and evaluating their quality and is directly related to visibility, or retroreflectivity, of the road marking. Road-marking service life, or in other words the level and the rate of their retroreflectivity degradation, affect the timing of the renewal of the marking, and thus the overall maintenance costs. By Smadi, Hawkins, Nlenanya, \& Aldemir-Bektas (2010), several factors affect the road markings service life, namely: type of material, road marking position (edge or centre), road marking age, annual average daily traffic (AADT), road type/ category, number of road markings (lines), type of asphalt surface on the road, speed limit, amount of salt, amount of abrasives and rate of winter road maintenance activity. In addition to this, glass beads are also an essential factor since their quality and quantity has an impact on road markings retroreflectivity, and thus their service life (Grosges, 2008; Zhang, Hummer, \& Rasdorf, 2009). The quality of glass beads depends on their granulation, refractive index, roundness and chemical coating, which allows for a tighter adhesion of the beads to the road marking material.

In the last twenty years, various researchers have developed several models for predicting the road markings service life. Factors such as AADT, initial retroreflectivity (note: initial retroreflectivity is road
Model

for Predicting

Road Markings

Service Life 
markings retroreflectivity after they have been applied), material type and colour, characteristics of the area where the road is located, road condition and road marking position have been considered when analysing and developing individual models.

One of the first researches related to road markings service life was conducted by Perrin, Martin, \& Hansen (1998). By a comparative analysis of colours and tapes used for marking the road, the researchers concluded that road markings retroreflectivity, or service life, is affected by the age of the material, AADT and road type. Based on the conclusions, Andrady (1997) developed a model for the service life of paint and thermoplastic road markings, by which the predicted service life of paint road markings is 18.80 months, and for thermoplastic road markings, it ranges from 7.80 months to 40.60 months. The road markings retroreflectivity has been modelled solely as a function of the time required for a road marking to reach the minimum retroreflectivity level of $100 \mathrm{mcd} / \mathrm{lx} / \mathrm{m}^{2}$.

Lee, Maleck, \& Taylor (1999) have determined the degradation rate of paint, thermoplastic and tape markings. The degradation of these materials was linearly modelled with extremely low accuracy $\left(R^{2}\right)$ from 0.14 to 0.18 . In conclusion, it was found that the average drop in all material retroreflectivity is $0.14 \%$ per day and that waterborne paints are the most cost-effective option for applying road markings.

Migletz, Graham, Harwood, \& Bauer (2001) summarised the results of four-year research related to predicting the service life of different materials used for the application of road markings. The service life of the materials varied depending on the geographical and road conditions in which the road marking was situated. The average service life expressed in months is as follows: waterborne and epoxy paints 10.40 and 23.00 months, respectively, thermoplastic material 26.20 months and polyurea materials 24.70 months. Based on the cumulative number of traffic passages (CTP) as the primary variable, the relationship between the coefficient of retroreflectivity and CTP has been quantified using different models such as linear and exponential model.

Abboud \& Bowman (2002) analysed the service life of waterborne paints and thermoplastic material. Using $150 \mathrm{mcd} / \mathrm{lx} / \mathrm{m}^{2}$ as a minimum level of retroreflection, the researchers developed logarithmic models for predicting the service life of road markings as a function of traffic volume. The models coefficient of determination $\left(R^{2}\right)$ range from 0.31 (for waterborne paints) to 0.58 (for thermoplastic material).

Lindly \& Wijesundera (2003) compared the service life of flat and profiled thermoplastic road markings, their maintenance costs and impact on safety and visibility in wet conditions. The results showed that the cumulative number of traffic passages has a higher correlation 
with the road marking retroreflectivity than the age of the road marking. Based on the results, the researchers proposed separate linear and exponential models for flat and for profiled thermoplastic road markings.

Sarasua, Clarke, \& Davis (2003) developed two models each for epoxy and thermoplastic materials, white and yellow, on asphalt and concrete road surface. The first model was nonlinear and was used to predict the value of road markings retroreflectivity shortly after the application when retroreflectivity is slightly increasing. The second model is linear and represents the degradation of retroreflectivity over a more extended period during the road marking service life. Factors potentially affecting the degradation of retroreflectivity, or the road markings service life, analysed in this study were road marking colour and type of material, type of road surface and AADT. Of the above variables, only the volume of traffic was found as a statistically unimportant variable. The accuracy of the models varies from 0.19 to 0.78 depending on the combination of material, colour and road surface. The average coefficient of determination $\left(R^{2}\right)$ of the first nonlinear model is 0.46 and of the second linear model 0.30 .

The research on the service life of white and yellow road markings applied in solvent-borne and waterborne paints resulted in linear, logarithmic and exponential models of retroreflectivity degradation of the markings for each separate research location with a minimum level of retroreflection set at $100 \mathrm{mcd} / \mathrm{lx} / \mathrm{m}^{2}$ (Kopf, 2004). The study also showed that retroreflectivity degradation of road markings with similar AADT and weather conditions varies significantly. The researcher states the following reasons for the variation: differences in the methods of road markings application, equipment and expertise of the contractor, variability in the accuracy of retroreflectivity measurement devices, problems related to the accuracy of device calibration and non-consistency of retroreflectivity measurement. Although the study developed several models, the accuracy for most of them is weak and varies considerably (from 0.033 to 0.732 ).

With smoothing spline and time series methods, Zhang \& Wu (2006) developed degradation models for thermoplastic materials, tapes and waterborne paints in which retroreflectivity is a function of time. Based on the results and model comparison, the researchers conclude that, with a few exceptions, both methods satisfactorily predict the degradation of road markings retroreflectivity for the following six months. Although the models have a satisfactory accuracy, the Zhang \& Wu (2006) state that there are limits of the research. They did not develop models including other factors affecting the road markings service life (such as the impact of winter maintenance activities of the
Model

for Predicting

Road Markings

Service Life 
road, road marking position, the volume of traffic), but instead, they obtained a general methodology for predicting the degradation of road marking retroreflectivity.

Fitch (2007) developed logarithmic models for predicting the retroreflectivity of epoxy paint, thermoplastic and polyurea road markings. The data was collected over three years on 25 roads, of which 19 had thermoplastic road markings, five had polyurea, and one had epoxy paint road markings. Retroreflectivity has been modelled as a function of traffic volume, time (road marking age) and characteristics of geographic regions in which the analysed roads are located. The research found that the volume of traffic has a significant impact and that the rate of degradation is less in warmer geographic regions compared to relatively colder areas. In addition, road marking age and winter maintenance activities of the road has proved to be the most influential factors on the degradation of retroreflectivity. Even though the obtained models have a relatively satisfactory accuracy ( $R^{2}$ from 0.53 to 0.87 depending on the material), their practical application is questionable because in the final models the retroreflectivity has been modelled solely as a function of time, that is road marking age. Factors such as traffic volume, characteristics of geographic regions and winter maintenance activities of the road have been analysed and compared separately so that, for instance, the degradation of road markings retroreflectivity has been modelled separately for roads with winter maintenance activities and those without winter maintenance activities. Afterwards, the researchers compared the degradation rate of road markings with each other to determine the importance of the impact of winter maintenance activities of the road on their degradation. Other factors have been analysed in the same way, and their impact was not finally determined (weighted) nor applied in the final model.

Sitzabee, Hummer, \& Rasdorf (2009) developed linear models for paint and thermoplastic road markings in which the retroreflectivity is a function of time, AADT, road marking colour and position (edge or centre lines). Although the accuracy of the model is relatively satisfactory ( $R^{2}$ equal to 0.60 for thermoplastic material and 0.75 for paint), the models did not pass the Shapiro-Wilk normality test. Therefore, as the researchers stress, the models are statistically questionable, which limits their application.

Hummer, Rasdorf, \& Zhang (2011) developed a linear mixed-effects model predicted the retroreflectivity degradation of paint white edge lines and yellow centre lines to 37.50 months and 38.90 months, respectively. 
The first model for predicting the service life of paint road markings, which included the winter maintenance activities of the road, has been developed by Mull \& Sitzabee (2011). The results showed that every winter maintenance activity of the road (snowplough activity) reduces the retroreflectivity of road markings by $3.22 \mathrm{mcd} / \mathrm{lx} / \mathrm{m}^{2}$, which altogether reduces road marking service life for more than a month. Furthermore, the AADT, although weak, had a statistically significant effect on the degradation of road markings.

Pike \& Songchitruksa (2015) analysed the service life of waterborne and epoxy paints, polyurea and thermoplastic road markings. For the research, the road markings were applied as longitudinal and transversal. The research resulted in an exponential model for predicting road markings service life for each type of material in which the retroreflectivity is a function of time and type of road surface. Although the accuracy $\left(R^{2}\right)$ of the model is satisfactory, ranging from 0.6411 to 0.9845 depending on the type of material and road surface, the shortfall of the research, as Pike \& Songchitruksa (2015) state, is the limited number of factors involved in the model. As the research was performed on two test fields prepared for this purpose, the model included only the road marking age, type of material and type of road surface. Therefore, the practical application of the model is questionable and limited.

The detailed analysis of previous research aimed at predicting the service life of road markings shows that most of the above models have relatively low coefficients of determination $\left(R^{2}\right)$, which means that model errors are high. Even models with high $R^{2}$ (Hummer, Rasdorf, \& Zhang, 2011; Mull \& Sitzabee, 2011; Sitzabee, Hummer, \& Rasdorf, 2009) either has statistically significant disadvantages or do not allow for modelling of the service life of all the most frequently used materials for road marking application.

Furthermore, the presented models do not consider all the factors affecting the degradation of retroreflectivity, which suggests that previous research have flaws limiting their application in road maintenance systems. Besides, most of the mentioned studies used handheld retroreflectometers (static method) to collect data on retroreflectivity. Handheld retroreflectometers, due to their small measuring range, are unable to measure retroreflectivity along the entire width and length of road markings, which sometimes leads to an incorrect evaluation. Namely, moving the static device by less than a centimetre in any direction on the road marking sometimes leads to significantly different measurements (Babić, Fiolić, \& Žilionienè, 2017).

The chronological presentation of prediction models for road marking service life and their characteristics are presented in Table 1.
Model

for Predicting

Road Markings

Service Life 
Table 1. Chronological presentation of prediction models for road marking service life

\begin{tabular}{|c|c|c|c|c|}
\hline Year & Researcher/s & Material & Factors & Model \\
\hline 1997 & Andrady & Thermoplastics & $\begin{array}{l}\text { Road marking age, } \\
\text { initial retroreflectivity }\end{array}$ & Logarithmic unavailable \\
\hline 1999 & $\begin{array}{l}\text { Lee, Maleck, } \\
\text { \& Taylor }\end{array}$ & $\begin{array}{l}\text { Waterborne paint, } \\
\text { thermoplastics, } \\
\text { tapes }\end{array}$ & Road marking age & $\begin{array}{l}\text { Linear } \\
\text { from } 0.14 \text { to } 0.18 \\
\text { depending on the material }\end{array}$ \\
\hline 2001 & $\begin{array}{l}\text { Migletz, } \\
\text { Graham, } \\
\text { Harwood, } \\
\text { \& Baver }\end{array}$ & $\begin{array}{l}\text { Waterborne paint, } \\
\text { thermoplastics, } \\
\text { polyurea material, } \\
\text { epoxy paint }\end{array}$ & $\begin{array}{l}\text { Cumulative number } \\
\text { of traffic passages, } \\
\text { initial retroreflectivity }\end{array}$ & $\begin{array}{l}\text { Linear and exponential } \\
\text { unavailable }\end{array}$ \\
\hline 2002 & $\begin{array}{l}\text { Abboud } \\
\& \text { Bowman }\end{array}$ & $\begin{array}{l}\text { Waterborne paint, } \\
\text { thermoplastics }\end{array}$ & $\begin{array}{l}\text { Road marking exposure } \\
\text { to vehicles (in thousands } \\
\text { of vehicles) }\end{array}$ & $\begin{array}{l}\text { Logarithmic } \\
\text { from } 0.31 \text { to } 0.58 \\
\text { depending on the material }\end{array}$ \\
\hline 2003 & $\begin{array}{l}\text { Lindly } \\
\text { \& Wijesundera }\end{array}$ & Thermoplastics & $\begin{array}{l}\text { Cumulative number } \\
\text { of traffic passages }\end{array}$ & $\begin{array}{l}\text { Linear and exponential } \\
0.53 \text { for linear } \\
\text { and } 0.67 \text { for exponential }\end{array}$ \\
\hline 2003 & $\begin{array}{l}\text { Sarasua, } \\
\text { Clarke, } \\
\text { \& Davis }\end{array}$ & $\begin{array}{l}\text { Thermoplastics, } \\
\text { epoxy paint }\end{array}$ & $\begin{array}{l}\text { Road marking colour, } \\
\text { type of material, AADT, } \\
\text { road marking age, } \\
\text { type of road surface }\end{array}$ & $\begin{array}{l}\text { Linear and nonlinear } \\
0.19 \text { for linear and } 0.78 \\
\text { for nonlinear }\end{array}$ \\
\hline 2004 & Kopf & $\begin{array}{l}\text { Waterborne } \\
\text { and solvent-borne } \\
\text { paint }\end{array}$ & $\begin{array}{l}\text { Road marking colour, } \\
\text { AADT, road marking age }\end{array}$ & $\begin{array}{l}\text { Linear, logarithmic } \\
\text { and exponential } \\
\text { from } 0.033 \text { to } 0.732\end{array}$ \\
\hline 2006 & $\begin{array}{l}\text { Zhang } \\
\& W u\end{array}$ & $\begin{array}{l}\text { Waterborne paint, } \\
\text { thermoplastics, } \\
\text { tapes }\end{array}$ & Road marking age & $\begin{array}{l}\text { Smoothing spline, } \\
\text { time series unavailable }\end{array}$ \\
\hline 2007 & Fitch & $\begin{array}{l}\text { Thermoplastics, } \\
\text { epoxy paint, } \\
\text { polyurea material }\end{array}$ & $\begin{array}{l}\text { Road marking age, } \\
\text { AADT, characteristics } \\
\text { of geographic regions }\end{array}$ & $\begin{array}{l}\text { Logarithmic } \\
\text { from } 0.53 \text { to } 0.87 \\
\text { depending on the material }\end{array}$ \\
\hline 2009 & $\begin{array}{l}\text { Sitzabee, } \\
\text { Hummer, } \\
\text { \& Rasdorf }\end{array}$ & $\begin{array}{l}\text { Paint, } \\
\text { thermoplastics }\end{array}$ & $\begin{array}{l}\text { Road marking age, AADT, } \\
\text { initial retroreflectivity, } \\
\text { road marking colour } \\
\text { and position }\end{array}$ & $\begin{array}{l}\text { Linear } \\
\text { from } 0.60 \text { to } 0.75 \\
\text { depending on the material }\end{array}$ \\
\hline 2011 & $\begin{array}{l}\text { Hummer, } \\
\text { Rasdorf, } \\
\text { \& Zhang, }\end{array}$ & $\begin{array}{l}\text { Solvent-borne } \\
\text { paint }\end{array}$ & $\begin{array}{l}\text { Road marking age, } \\
\text { initial retroreflectivity }\end{array}$ & Mixed linear equal to 0.678 \\
\hline 2011 & $\begin{array}{l}\text { Mull } \\
\text { \& Sitzabee }\end{array}$ & $\begin{array}{l}\text { Solvent-borne } \\
\text { paint }\end{array}$ & $\begin{array}{l}\text { Road marking age, AADT, } \\
\text { initial retroreflectivity, } \\
\text { winter road maintenance } \\
\text { activities }\end{array}$ & Linear equal to 0.76 \\
\hline 2015 & $\begin{array}{l}\text { Pike } \\
\text { \& Songchitruksa }\end{array}$ & $\begin{array}{l}\text { Waterborne } \\
\text { and epoxy paint, } \\
\text { polyurea material, } \\
\text { thermoplastics }\end{array}$ & $\begin{array}{l}\text { Road marking age, } \\
\text { initial retroreflectivity }\end{array}$ & $\begin{array}{l}\text { Exponential } \\
\text { from } 0.64 \text { to } 0.98 \\
\text { depending } \\
\text { on the material }\end{array}$ \\
\hline
\end{tabular}




\section{Methodology}

The research aims to develop models for predicting the service life of road markings applied in solvent-borne paint, thermoplastics and agglomerate cold plastics. For this purpose, 115 single carriageway state roads were selected, which makes for $5218.00 \mathrm{~km}$ of solvent-borne paint road markings. Of 115 analysed road markings, 63 are centre lines in the total length of $2845.90 \mathrm{~km}$, while the remaining ones are 52 edge lines in a total length of $2372.10 \mathrm{~km}$.

As for the thermoplastic and agglomerate cold plastic road markings, 30 roads were selected for each of the materials as mentioned above. A total of $579.00 \mathrm{~km}$ of thermoplastic road markings was included, of which $293.00 \mathrm{~km}$ of centre lines and 286 of edge lines. The agglomerate cold plastic road markings were analysed in the total length of $497.90 \mathrm{~km}$, of which $292.70 \mathrm{~km}$ of centre lines and $205.20 \mathrm{~km}$ of edge lines.

The retroreflectivity of road markings, as the primary indicator of their service life, was measured using the dynamic method twice on every analysed road. The first measurement was done in a period between 30 days and 60 days after the application or renewal of the road marking and the second measurement after the winter (existing marking) as defined by the Guidelines and Technical Requirements in Croatia (Hrvatske ceste d.o.o., 2010).

The dynamic test method is a contemporary method in which road marking retroreflectivity is measured with a dynamic retroreflectometer mounted on the left or right side of a measuring vehicle, depending on whether the centre or edge line is to be measured. The device enables the measurement of retroreflectivity continuously, along the entire road section. For this research, the measuring interval was set at $50 \mathrm{~m}$. In other words, the device has consistently measured the road marking retroreflectivity, and it showed its average value every $50 \mathrm{~m}$. The arithmetic mean of the retroreflectivity value of all these $50 \mathrm{~m}$ intervals on the road was taken as the relevant value of the road marking retroreflectivity. These measurements were taken in the period from 2011 to 2015.

Table 2 shows the descriptive statistics of the measured values of road markings retroreflectivity for each analysed material. It is visible that the highest retroreflectivity of renewed and existing road markings was achieved with agglomerate cold plastics, followed by thermoplastics, while the lowest levels were observed in solvent-borne paint.

In addition to data on retroreflectivity, other data have also been collected, which, by the existing literature, affect the degradation of road marking retroreflectivity, or their service life. These data (independent variables) include road marking age, AADT of passenger and commercial
Model

for Predicting

Road Markings

Service Life 
Table 2. Descriptive statistics of the measured values of road markings retroreflectivity

\begin{tabular}{|c|c|c|c|c|c|}
\hline \multirow[t]{2}{*}{ Retroreflectivity } & \multirow{2}{*}{$\begin{array}{l}\text { Data } \\
\text { set }\end{array}$} & Minimum & Maximum & $\begin{array}{c}\text { Arithmetic } \\
\text { mean }\end{array}$ & $\begin{array}{l}\text { Standard } \\
\text { deviation }\end{array}$ \\
\hline & & \multicolumn{4}{|c|}{$\mathrm{mcd} / \mathrm{lx} / \mathrm{m}^{2}$} \\
\hline \multicolumn{6}{|c|}{ Solvent-borne paint } \\
\hline Renewed & 115 & 153 & 391 & 261.71 & 41.54 \\
\hline Existing & 115 & 41 & 275 & 151.30 & 48.85 \\
\hline \multicolumn{6}{|c|}{ Thermoplastics } \\
\hline Renewed & 30 & 300 & 384 & 346.13 & 23.68 \\
\hline Existing & 30 & 201 & 298 & 242.53 & 22.09 \\
\hline \multicolumn{6}{|c|}{ Agglomerate cold plastics } \\
\hline Renewed & 30 & 455 & 653 & 574.43 & 56.00 \\
\hline Existing & 30 & 306 & 591 & 452.63 & 79.69 \\
\hline
\end{tabular}

vehicles, road marking position, winter road maintenance activity (the number of snowplough passes during the winter period) and the average speed limit on the road.

The impact of individual variables on the road marking service life was examined by conducting the bivariate correlation and multiple regression analysis. The final model for each material includes only variables whose statistical significance is more than $95 \%$. The retroreflectivity of road markings after a certain period has been a dependent variable in the research. Based on a $Q-Q$ plot, it was concluded that the dispersion of variables or their deviation from the normal distribution is negligible, i.e. that all used variables are normally distributed, which satisfies the requirement for linear regression.

\section{Results}

\subsection{Model for predicting the service life of solvent-borne paint road markings}

The following variables were used for predicting retroreflectivity of existing solvent-borne paint road markings that is road-marking retroreflectivity after a certain period (dependent variable): initial retroreflectivity, road-marking age, road marking position, AADT divided to passenger and commercial vehicles, winter road maintenance activity and the average speed limit on the road. 
The researchers conducted a multiple regression analysis to determine the extent to which, based on statistically significant predictors, it is possible to predict retroreflectivity of existing road markings, and thus their service life, and to define the level of contribution of each predictor.

The multiple regression analysis found that four variables were statistically significant, namely: initial retroreflectivity $(p=0.000)$, road-marking age $(p=0.042)$, position $(p=0.001)$ and winter maintenance activity of the road $(p=0.000)$.

Based on the results of the multiple regression analysis, the final model for predicting retroreflectivity of solvent-borne paint road markings is:

$$
R_{L}=70.699+0.623 R_{\text {Linitial }}-0.139 t-21.891 p-2.145 r,
$$

where $R_{L}$ - retroreflectivity of existing $\mathrm{road}$ marking, $\mathrm{mcd} / \mathrm{lx} / \mathrm{m}^{2}$; $R_{\text {Linitial }}$ - road marking initial retroreflectivity after renewal, $\mathrm{mcd} / \mathrm{lx} / \mathrm{m}^{2}$; $t$ - road marking age, days; $p$ - road marking position $(1=$ centre line, 0 = edge line); $r$ - amount of winter road maintenance activity, numbers (of snowplough passes).

The coefficient of determination $\left(R^{2}\right)$ of the model is 0.56 , which ultimately means that the four predictors explain $56 \%$ of the variance of the criterion, that is of the dependent variable.

\subsection{Model for predicting the service life of thermoplastic road markings}

The following five predictors were used for predicting the service life of thermoplastic road markings: initial retroreflectivity, road-marking age, road marking position, AADT and winter maintenance activity of the road.

The multiple regression analysis found that two variables were statistically significant predictors, namely: initial retroreflectivity $(p=0.030)$ and road marking age $(p=0.003)$.

The final model for predicting the service life of thermoplastic road markings is as follows:

$$
R_{L}=225.120+0.346 R_{\text {Linitial }}-0.234 t,
$$

where $R_{L}$ - retroreflectivity of existing $\mathrm{road}$ marking, $\mathrm{mcd} / \mathrm{lx} / \mathrm{m}^{2}$; $R_{\text {Linitial }}$ - road marking initial retroreflectivity after renewal, $\mathrm{mcd} / \mathrm{lx} / \mathrm{m}^{2}$; $t$-road marking age, days.

The coefficient of determination $\left(R^{2}\right)$ of the final model is 0.414 , representing a drop by $13 \%$ compared to the initial model involving all five predictors. This drop in the predictive accuracy of the model suggests that other predictors, although not found as statistically
Model

for Predicting

Road Markings

Service Life 
significant in the model, to a certain extent still affect the service life of road marking. Given the limited sample used in this study (30 samples), it is possible that some of the predictors that were not found as statistically significant here would prove to be so in a larger sample.

\subsection{Model for predicting the service life of agglomerate cold plastic road markings}

Since thermo and cold plastic belong to the group of plastic materials, the same five variables used for thermoplastic were also deployed for modelling the service life of agglomerate cold plastic road markings (initial retroreflectivity, road marking age, road marking position, and AADT and winter maintenance activity of the road).

The multiple regression analysis found that four variables were statistically significant predictors, namely: initial retroreflectivity $(p=0.000)$, road-marking age $(p=0.000)$, road-marking position $(p=0.000)$ and winter maintenance activity of the road $(p=0.002)$.

Finally, based on initial retroreflectivity, road marking age and position and winter maintenance activity of the road, the final model was obtained:

$$
R_{L}=90.583+1.007 R_{\text {Linitial }}-0.345 t-35.642 p-2.535 r,
$$

where $R_{L}$ - retroreflectivity of existing road marking, $\mathrm{mcd} / \mathrm{lx} / \mathrm{m}^{2}$; $R_{\text {Linitial }}$ - road marking initial retroreflectivity after renewal, $\mathrm{mcd} / \mathrm{lx} / \mathrm{m}^{2}$; $t$ - road marking age, days; $p$ - road marking position $(1=$ centre line, 0 = edge line); $r$ - amount of road winter maintenance activity, numbers (of snowplough passes).

The coefficient of determination $\left(R^{2}\right)$ of the final model is 0.950 , which means that the stated predictors explain up to $95 \%$ of the variance of the dependent variable.

\subsection{Verification of models designed to predict road markings service life}

The researchers verified the accuracy of the obtained models based on a new set of data that was not used in obtaining the final models for predicting the road markings service life. The data used for model verification were related to those variables that were found as statistically significant in each model. The accuracy of the modelled retroreflectivity was verified using the real retroreflectivity data of the existing road markings measured using the dynamic method (Hrvatske ceste d.o.o., 2010). 
The results of the verification show that the average measured retroreflectivity of the existing road markings applied in solvent-borne paint is $173.97 \mathrm{mcd} / \mathrm{lx} / \mathrm{m}^{2}$, while the average modelled retroreflectivity of the same material is $170.96 \mathrm{mcd} / \mathrm{lx} / \mathrm{m}^{2}$. The average absolute difference between the measured and the modelled retroreflectivity is $10.40 \mathrm{mcd} / \mathrm{lx} / \mathrm{m}^{2}$ or $6.18 \%$, which suggests that the final model for predicting the service life of solvent-borne paint road markings is satisfactorily accurate. Additionally, the data obtained based on the final model, as shown in the Eq. (1), and the minimum levels of retroreflectivity required by drivers and defined in the previous research (Debaillon, Carlson, He, Schnell, \& Aktan, 2007; Graham, Harrold, \& King, 1996; Loetterle, Beck, \& Carlson, 2000; Parker \& Meja, 2003) enabled the calculation of the markings service life. Researchers calculated that the service life of solvent-borne paint road markings with the minimum level of retroreflectivity of $100 \mathrm{mcd} / \mathrm{lx} / \mathrm{m}^{2}$ is 753.61 days, while with the minimum retroreflectivity level of $150 \mathrm{mcd} / \mathrm{lx} / \mathrm{m}^{2}$ it is 393.60 days. Accordingly, this leads to a conclusion that the service life of solvent-borne paint road markings is between one and two years, which is in line with recent scientific research (Hummer, Rasdorf, \& Zhang, 2011; Mull \& Sitzabee, 2011). In addition, the obtained service life is somewhat longer compared to the knowledge and practice (Migletz, Fish, \& Graham, 1994; Texas Department of Transportation, 2004). This is possibly due to technological advancement in production, which leads to better quality materials with longer service life. Furthermore, the improvement of the processes for applying road markings also contributes to the longer service life of road markings.

For thermoplastic road markings, the average absolute difference between the measured and the modelled retroreflection is $38.31 \mathrm{mcd} / \mathrm{lx} / \mathrm{m}^{2}$ or $13.05 \%$. The calculated service life, by the Eq. (2), shows that for achieving minimum retroreflectivity levels of $100 \mathrm{mcd} / \mathrm{lx} / \mathrm{m}^{2}$ and $150 \mathrm{mcd} / \mathrm{lx} / \mathrm{m}^{2}$ thermoplastic markings requires 1097.76 days and 884.09 days or 3.01 years and 2.42 years respectively, which is in line with existing knowledge (Migletz, Fish, \& Graham, 1994; Migletz, Graham, Harwood, \& Bauer 2001; Texas Department of Transportation, 2004).

The absolute difference between the modelled and the real retroreflectivity value of agglomerate cold plastic road markings is $64.31 \mathrm{mcd} / \mathrm{lx} / \mathrm{m}^{2}$ or $11.72 \%$. The service life of the road markings, with the minimum level of retroreflectivity of $100 \mathrm{mcd} / \mathrm{lx} / \mathrm{m}^{2}$ and $150 \mathrm{mcd} / \mathrm{lx} / \mathrm{m}^{2}$, by the Eq. (3), has been calculated at 1581.14 days and 1436.21 days, or 4.33 years and 3.93 years, respectively. This finding is also in line with the practical knowledge of the service life of cold plastic (Bahar, Masliah, Erwin, Tan, \& Hauer, 2006).
Model

for Predicting

Road Markings

Service Life 
Table 3. Verification results of designed models

\begin{tabular}{|c|c|c|c|c|c|}
\hline \multirow{3}{*}{ Model } & \multirow{3}{*}{$\begin{array}{l}\text { Data } \\
\text { set }\end{array}$} & \multicolumn{2}{|c|}{$\begin{array}{c}\text { Average } \\
\text { retroreflection }\end{array}$} & \multirow{2}{*}{\multicolumn{2}{|c|}{$\begin{array}{l}\text { Average road marking service } \\
\text { life in days by }\end{array}$}} \\
\hline & & measured & modelled & & \\
\hline & & \multicolumn{2}{|c|}{$\mathrm{mcd} / \mathrm{lx} / \mathrm{m}^{2}$} & $100 \mathrm{mcd} / \mathrm{Ix} / \mathrm{m}^{2}$ & $150 \mathrm{mcd} / \mathrm{lx} / \mathrm{m}^{2}$ \\
\hline Solvent-borne paint & 30 & 173.97 & 170.96 & 753.61 & 393.60 \\
\hline Thermoplastics & 10 & 291.20 & 252.89 & 1097.76 & 884.09 \\
\hline $\begin{array}{l}\text { Cold agglomerate } \\
\text { plastics }\end{array}$ & 10 & 547.10 & 482.79 & 1581.14 & 1436.21 \\
\hline
\end{tabular}

Table 3 shows the results of the verification and the average service life of road markings applied in each material.

The results of the verification lead to the conclusion that all the three developed models have errors within a satisfactory level and as such are suitable for use in optimising road markings maintenance activities.

\section{Discussion}

The research aimed to develop models for predicting the service life of road markings applied in three most commonly used materials, namely: solvent-borne paint, thermoplastics and agglomerate cold plastics. Although several models for predicting the service life of road markings have been developed so far, they have certain limitations due to which they do not predict the road markings service life accurately enough, which significantly limits their application in optimising the road markings maintenance activities.

The model for predicting the service life of solvent-borne paint road markings includes four variables that were proven as statistically significant in the analysis (initial retroreflectivity, road marking age and position and winter maintenance activity of the road). In most of the existing literature, the AADT had a weak but statistically significant impact. On the other hand, in this research, it proved statistically insignificant.

A possible reason for this is the size of the sample. Namely, this research analysed $5218.00 \mathrm{~km}$ of road markings applied in solvent-borne paint, which is much more than recent research (Mull \& Sitzabee, 2011) where AADT had a weak but statistically significant impact. It is possible that the increase of the sample allowed obtaining a more accurate picture of the impact of every individual factor. The coefficient of determination 
$\left(R^{2}\right)$ of the obtained model is 0.560 , and the verification on the new set of data shows that the difference between the real and the modelled retroreflectivity value is satisfactory (6.18\%). Besides, based on the obtained model and the minimum levels of retroreflectivity required by drivers, the total service life of solvent-borne paint road markings has been calculated to two (for $100 \mathrm{mcd} / \mathrm{lx} / \mathrm{m}^{2}$ ) and one year (for $150 \mathrm{mcd} / \mathrm{lx} / \mathrm{m}^{2}$ ).

Five variables were analysed to develop the model for predicting the service life of thermoplastic road markings, two of which were found as statistically significant (initial retroreflectivity and road marking age). The total accuracy of the model is 0.414 . Compared to the initial model, which included all five predictors and whose $R^{2}$ is 0.543 , the accuracy of the final model was reduced by $13 \%$. This suggests that other predictors, although not found as statistically significant in the model, to a certain extent still affect the road marking service life. Given the limited sample used in this research (30 samples), it is possible that some of the predictors that were not found as statistically significant here would prove to be so in a larger sample (primarily the impact of road winter maintenance activity).

On the other hand, similarly as with solvent-borne paint, the AADT proved to be a negligible factor, although, in the available literature, the results are mixed. Possibly, this is because thermoplastic materials are extremely compact and robust and are applied in a thicker layer, which is why the impact of traffic is insignificant. Despite this, the model verification showed a satisfactory accuracy of the final model (the difference between the real and the modelled retroreflection value is $13.05 \%$ ). The predicted service life of thermoplastic road markings is between 3.01 years and 2.42 years, depending on the minimum level of retroreflectivity $\left(100 \mathrm{mcd} / \mathrm{lx} / \mathrm{m}^{2}\right.$ and $\left.150 \mathrm{mcd} / \mathrm{lx} / \mathrm{m}^{2}\right)$.

Four variables (initial retroreflectivity, road marking age and position, and winter maintenance activity of the road) were proven as statistically significant for modelling the service life of agglomerate cold plastics. In this case, also, the AADT has not proved to be statistically significant since cold plastic, as well as thermoplastics, is a material of higher strength and compactness, which is why the potential impact of traffic on its degradation is negligible. The coefficient of determination $\left(R^{2}\right)$ of the final model is as high as 0.950 , and the verification showed that the difference between the real and the modelled retroreflectivity value is $11.72 \%$. The service life of the material was calculated based on the model, and it is between 4.33 years and 3.93 years, depending on the minimum level of retroreflectivity (100 mcd $/ \mathrm{lx} / \mathrm{m}^{2}$ and $\left.150 \mathrm{mcd} / \mathrm{lx} / \mathrm{m}^{2}\right)$, which is consistent with the general knowledge on the service life of cold plastic road markings. Here it is important to emphasise that, as far as it is known to authors of this paper, a model for predicting the service life of agglomerate cold plastic road markings is the first such model in the scientific literature.
Model

for Predicting

Road Markings

Service Life 


\section{Conclusions}

1. Road markings are an essential road safety element, which provides drivers with visual guidance along the road. Since their quality degrades over time, road markings need to be maintained in a timely and appropriate manner. One way of optimising maintenance activities is by applying prediction models. The results of this study show accurately prediction the service life of road markings by using between two and four main variables depending on the material. Namely, all three developed models have predicted accuracy in a satisfactory manner, which allows their efficient application in the optimisation of road markings maintenance activities. By applying the model, road authorities are able to plan their resources, improve the quality of the contractors, and ultimately optimise road marking maintenance costs ensuring the desired level of quality in the meanwhile. Furthermore, well-maintained road markings will provide drivers with the visibility needed in the night-time and lowvisibility conditions, thus enabling them to enjoy a more comfortable and safer journey, which will ultimately have positive effects on overall road safety.

2. Although the models show satisfactory accuracy, given the limited sample of plastic materials (30 samples for each type of plastic material), it is necessary to conduct further research to verify the obtained models. Moreover, further research should focus on examining other factors as well, that are uncovered in this research due to lack of data. This primarily concerns the type and quality of glass beads, the type and condition of the road surface and the amount of salt and abrasives. Namely, since road markings retroreflection is achieved with glass beads, their quality, in terms of granulation, refractive index, roundness and chemical coating, which allows for a tighter adhesion of the beads to the road marking material, has a significant impact on the road markings service life. In addition, salt and abrasives damage glass beads because of friction arising from vehicles passing. Furthermore, previous research, to some extent suggests that the type and condition of the road surface differently affect the longevity of each material. This finding is mainly related to the different bonding conditions between materials and asphalt or concrete pavements and their roughness.

3. Since the presented models have been developed based on the data collected on the roads across the Republic of Croatia, which is climatically diverse, from mountain areas with frequent snow to the Mediterranean parts, their efficient use in other countries 
is promising. Nevertheless, further evaluation and verification is welcomed to determine their accuracy on a larger sample more precisely and to verify their predictive ability for other road categories, e.g. express roads or motorways.

\section{REFERENCES}

Abboud, N., \& Bowman, B. L. (2002). Cost-and longevity-based scheduling of paint and thermoplastic striping. Transportation Research Record, 1794(1), 55-62. https://doi.org/10.3141/1794-07

Andrady, A. L. (1997). Pavement Marking Materials: Assessing Environment Friendly Performance (Vol. 392). Transportation Research Board.

Avelar, R. E., \& Carlson, P. J. (2014). Link between pavement marking retroreflectivity and night crashes on Michigan two-lane highways. Transportation research record, 2404(1), 59-67. https://doi.org/10.3141/2404-07

Babić, D., Fiolić, M., \& Žilionienė, D. (2017). Evaluation of static and dynamic method for measuring retroreflection of road markings. Građevinar, 69(10), 907-914. https://doi.org/10.14256/JCE.2010.2017

Babić, D., Ščukanec, A., \& Babić, D. (2016). Determining the correlation between daytime and night time road markings visibility. Baltic Journal of Road \& Bridge Engineering (Baltic Journal of Road \& Bridge Engineering), 11(4). https://doi.org/10.3846/bjrbe.2016.33

Bahar, G., Masliah, M., Erwin, T., Tan, E., \& Hauer, E. (2006). Pavement marking materials and markers: Real-world relationship between retroreflectivity and safety over time (No. Project 17-28).

Bektas, B. A., Gkritza, K., \& Smadi, O. (2016). Pavement marking retroreflectivity and crash frequency: segmentation, line type, and imputation effects. Journal of Transportation Engineering, 142(8), 04016030. https://doi.org/10.1061/(asce)te.1943-5436.0000863

Carlson, P. J., Park, E. S., \& Kang, D. H. (2013). Investigation of longitudinal pavement marking retroreflectivity and safety. Transportation Research Record, 2337(1), 59-66. https://doi.org/10.3141/2337-08

Davidse, R., van Driel, C., \& Goldenbeld, C. (2004). The effect of altered road markings on speed and lateral position: a meta-analysis (Vol. 2003, No. 31).

Debaillon, C., Carlson, P. J., He, Y., Schnell, T., \& Aktan, F. (2007). Updates to research on recommended minimum levels for pavement marking retroreflectivity to meet driver night visibility needs (No. FHWA-HRT-07-059). Turner-Fairbank Highway Research Center.

Fitch, J. (2007). Pavement marking durability statewide (No. 2007-3).

Graham, J. R., Harrold, J. K., \& King, L. E. (1996). Pavement marking retroreflectivity requirements for older drivers. Transportation Research Record, 1529(1), 65-70. https://doi.org/10.1177/0361198196152900108 
Grosges, T. (2008). Retro-reflection of glass beads for traffic road stripe paints. Optical Materials, 30(10), 1549-1554.

https://doi.org/10.1016/j.optmat.2007.09.010

Hrvatske ceste d.o.o. (2010). Smjernice i tehnički zahtjevi za izvođenje radova na obnavljanju oznaka na kolniku - Horizontalna signalizacija (Croatian Roads ltd.: Guidelines and Technical Requirements for Road Marking Renewal Works Horizontal Signalization), Zagreb, Croatia (in Croatian).

Hummer, J. E., Rasdorf, W., \& Zhang, G. (2011). Linear mixed-effects models for paint pavement-marking retroreflectivity data. Journal of transportation engineering, 137(10), 705-716.

https://doi.org/10.1061/(asce)te.1943-5436.0000283

Industrial Commercial Striping. (2015). A Brief History of Road Surface Marking and Striping.

Kopf, J. (2004). Reflectivity of pavement markings: Analysis of retroreflectivity degradation curves (No. WA-RD 592.1,). Washington State Department of Transportation.

Lee, J. T., Maleck, T. L., \& Taylor, W. C. (1999). Pavement making material evaluation study in Michigan. Institute of Transportation Engineers. ITE Journal, 69(7), 44.

Lindly, J. K., \& Wijesundera, R. K. (2003). Evaluation of profiled pavement markings (No. UTCA Report Number 01465). University Transportation Center for Alabama.

Loetterle, F. E., Beck, R. A., \& Carlson, J. (2000). Public perception of pavement-marking brightness. Transportation Research Record, 1715(1), 51-59. https://doi.org/10.3141/1715-08

Migletz, J., Fish, J. K., \& Graham, J. L. (1994). Roadway delineation practices handbook (No. FHWA-SA-93-001). United States. Federal Highway Administration.

Migletz, J., Graham, J. L., Harwood, D. W., \& Bauer, K. M. (2001). Service life of durable pavement markings. Transportation Research Record, 1749(1), 13-21. https://doi.org/10.3141/1749-03

Miller, T. R. (1992). Benefit-cost analysis of lane marking (No. 1334).

Mull, D. M., \& Sitzabee, W. E. (2011). Paint pavement marking performance prediction model. Journal of Transportation Engineering, 138(5), 618-624. https://doi.org/10.1061/(asce)te.1943-5436.0000360

Parker, N. A., \& Meja, M. S. (2003). Evaluation of performance of permanent pavement markings. Transportation Research Record, 1824(1), 123-132. https://doi.org/10.3141/1824-14

Perrin, J., Martin, P. T., \& Hansen, B. G. (1998, January). A comparative analysis of pavement marking materials. In Transportation Research Board Annual Meeting (pp. 98-130).

Pike, A. M., \& Songchitruksa, P. (2015). Predicting pavement marking service life with transverse test deck data. Transportation Research Record, 2482(1), 16-22. https://doi.org/10.3141/2482-03

Retting, R. A., \& Farmer, C. M. (1998). Use of pavement markings to reduce excessive traffic speeds on hazardous curves. ITE journal, 68, 30-41. 
Sarasua, W. A., Clarke, D. B., \& Davis, W. J. (2003). Evaluation of interstate pavement marking retroreflectivity (No. FHWA-SC-03-01,).

Shinar, D., Rockwell, T. H., \& Malecki, J. A. (1980). The effects of changes in driver perception on rural curve negotiation*. Ergonomics, 23(3), 263-275. https://doi.org/10.1080/00140138008924739

Sitzabee, W. E., Hummer, J. E., \& Rasdorf, W. (2009). Pavement marking degradation modeling and analysis. Journal of infrastructure systems, 15(3), 190-199. https://doi.org/10.1061/(asce)1076-0342(2009)15:3(190)

Smadi, O., Hawkins, N., Nlenanya, I., \& Aldemir-Bektas, B. (2010). Pavement markings and safety (No. IHRB Project TR-580). Iowa State University. Institute for Transportation.

Smadi, O., Souleyrette, R. R., Ormand, D. J., \& Hawkins, N. (2008). Pavement marking retroreflectivity: analysis of safety effectiveness. Transportation Research Record, 2056(1), 17-24. https://doi.org/10.3141/2056-03

Texas Department of Transportation (2004). Pavement Marking Handbook. Report. Texas, USA.

World Health Organization (2017). Road Traffic Injuries.

Zhang, G., Hummer, J. E., \& Rasdorf, W. (2009). Impact of bead density on paint pavement marking retroreflectivity. Journal of Transportation Engineering, 136(8), 773-781. https://doi.org/10.1061/(asce)te.1943-5436.0000142

Zhang, Y., \& Wu, D. (2006). Methodologies to predict service lives of pavement marking materials. In Journal of the Transportation Research Forum, 45(3). https://doi.org/10.5399/osu/jtrf.45.3.601
Model for Predicting Road Markings Service Life 